\title{
Exploring Research Data Management in the Visual Arts
}

\author{
Leigh Garrett \\ University for the \\ Creative Arts \\ Faulkner Road, \\ Farnham, Surrey GU9 7DS \\ Igarrett@ucreative.ac.uk
}

\author{
Robin Burgess \\ Glasgow School of Art \\ 167 Renfrew Street, \\ Glasgow G3 6RQ \\ r.burgess@gsa.ac.uk
}

\author{
Amy Robinson \\ University for the \\ Creative Arts \\ Faulkner Road, \\ Farnham, Surrey GU9 7DS \\ arobinson@ucreative.ac.uk
}

\author{
Anne Spalding \\ University for the \\ Creative Arts \\ Faulkner Road, \\ Farnham, Surrey GU9 7DS \\ aspalding2@ucreative.ac.uk
}

\section{INTRODUCTION}

Research data is a valuable resource and, with appropriate management, it has much to offer learning, teaching, research and knowledge transfer in the visual arts. However in 2011, at the outset of the KAPTUR project, very little was known about the management of research data: none of the specialist arts institutions had policies or infrastructure and evidence suggested that practice was ad hoc, left to individual researchers and teams with little support or guidance. Funded by JISC KAPTUR, led by the Centre for Digital Scholarship, a Research Centre of the University for the Creative Arts, and working in partnership with the Glasgow School of Art; Goldsmiths, University of London; and University of the Arts London the project team sought to resolve this lack of awareness.

The need was imperative, across the higher education sector, research councils, institutions, teams and researchers are under pressure to make publicly funded research data freely available, and in line with the Research Councils UK guidance, the publication of data was increasingly a requirement of funding. However, by its nature, research outputs and data in the visual arts is highly complex and varied, often comprising a wide variety of outputs and formats which present researchers, information managers and technology teams with many discipline specific issues.

The team began with an environmental assessment which focused on terminology, the role of the visual arts researcher, how visual arts research data is created, used and preserved. This was followed by a technical analysis which considered two key questions: What do researchers and their institutions need to support research data management in the visual arts? What technologies exist to fulfil these

requirements? Finally the team developed a series of capacity building tools, these included: three skills development sessions; research data management policies; a series of case studies; a costing and business model; and participation in a range of national and international dissemination activities.

With an award from the Arts and Humanities Research Council (AHRC) in 2013, this work was extended by the Centre in partnership with Falmouth University and Glasgow School of Art, which now seeks to create a series of tailored skills development materials, focusing on research data management needs of early careers researchers and postgraduate students, over the course of the current academic year.

\section{THE WORKSHOP}

This workshop will enable participants to explore the nature of research data in the visual arts and the essential elements of its appropriate management.

For researchers, the effective management of research data helps validate and contextualise the outputs of artistic research, while at the same time supports the research method by enabling researchers to work more effectively and to mitigate against the risk of data lost. In addition, many funders now require data management plans to be submitted as part of the funding process.

Utilising emerging knowledge and practice in the visual arts, participants will have an opportunity to:

- examine the nature of research data in the visual arts and why is it important and to whom; 
- learn about the key requirements of good research data management and what to consider when planning your own approach;

- explore the vital elements of the data management requirements to help support your research funding proposal.
The workshop will consist of a mixture of presentations and participant led activities. It will be an abridged version of the full programme currently being piloted so it will offer only a basic introduction to this vast and complex area; however participants will be offered access to the online pilot toolkits for independent review following the session.

\section{Exploring Research Data Management in the Visual Arts}

Robin Burgess ${ }^{1} .$. Leigh Garrett ${ }^{2}$... Amy Robinson ${ }^{2}$... Anne Spalding ${ }^{2}$

1. The Glasgow School of Art, 167 Renfrew Street, Glasgow, G3 6RQ, United Kingdom (c.burgessegsa.ac.uk) 2. The University of the Creative Arts, Farnham

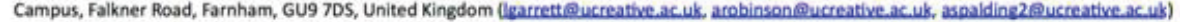

\begin{tabular}{|l|l|l|}
\hline \multicolumn{1}{|c|}{ What is research data? } & What are the issues? & Why bother? Benefits... \\
\hline $\begin{array}{l}\text { Journals, } \\
\text { sketchbooks, } \\
\text { found objects, } \\
\text { documents, } \\
\text { diaries, data } \\
\text { sets, notes, } \\
\text { recordings, } \\
\text { videos, texts, } \\
\text { sounds... } \\
\text { "Stuffl" }\end{array}$
\end{tabular}

\begin{tabular}{|l|l|}
\hline How to manage data? & Preservation and Re-use
\end{tabular}

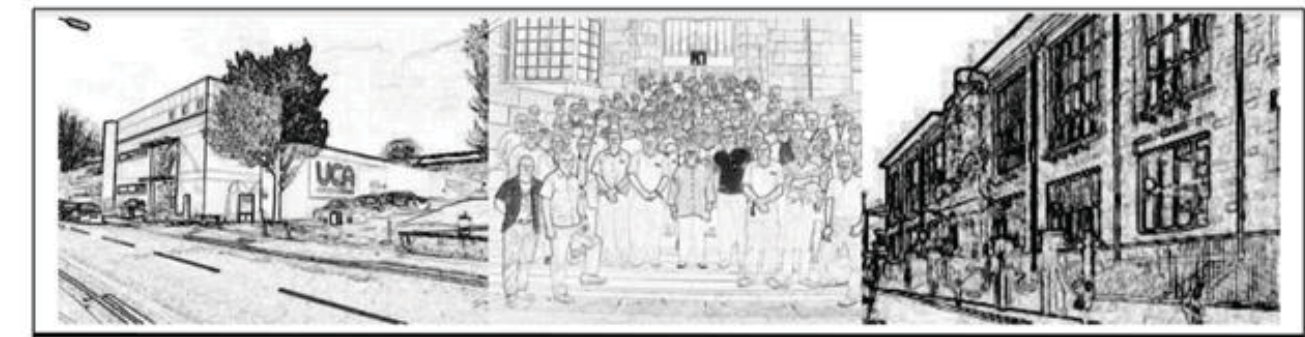

The Research Community - Helping students and researchers with data management

vads $4 R$ From KAPTUR to VADS4R

\section{http://www.vads.ac.uk/kaptur and http://www.vads4r.vads.ac.uk}

Image Acknowledgments: Copyright: Gil Bear (burgessandhearegmailicom). Website: www burgessandbearco,uk and wwwefacebookccom/burgessbear 